\title{
Hydrodynamics of Supercavitating Bodies at an Angle of Attacks under Conditions of Considerable Effect of Fluid Weightiness and Closeness of Free Border
}

\author{
V. Kochin ${ }^{1}$, V. Moroz ${ }^{1}$, V. Serebryakov ${ }^{1}$, and N. Nechitailo ${ }^{2}$ \\ 1. Institute of Hydromechanics of National Academy of Sciences 8/4 Zheliabov Str., 03680 Kiev, Ukraine \\ 2. Naval Surface Warfare Center, G24, 6138 Norc Ave., suite 313Dahlgren, Virginia 22448-5157, USA
}

\begin{abstract}
We present the results of theoretical and experimental studies of flow processes of extended axisymmetric cavitators during motion near a free surface taking into account a considerable effect of fluid weightiness. The main objective of work is to study ways of reduction of fluid weightiness effect using lift at cavitator and other body (hull) elements within a cavity, in order to apply this way of drag reduction for a range of considerably lower motion speeds.
\end{abstract}

Key words: Fluid mechanics, supercavitation, gravity influence.

\section{Introduction}

The increase in motion velocities of surface vessels is attributed to solving the following two basic problems:

- to overcome a very sharp drag increase and, accordingly, to reduce power losses;

- to reduce wave loads which sharply increase with motion velocity, especially under storm conditions.

One of effective ways of solving both problems is using, as the basic part of a surface vessel, a system of underwater hulls moving at small depth near free water surface, which make it possible to avoid considerable wave loads. On the other hand, this implies application of supercavitation flow mode for the major part of underwater hulls' surfaces, which provides a drastic drag drop. However, application of supercavitation for practical—not very high — range of motion velocities of hulls/bodies near perturbed water surface requires solving several basic problems related to high probability of large-scale deformations of a

Corresponding author: Vladimir Serebryakov, Ph.D., research fields: high speed hydrodynamic-supercavitation, E-mail: serebryakov_vladimir@yahoo.com. cavity occurring under action of gravity, closeness of free border and effect of waves on its surface. Among those, one of the most strong factors is effect of a free border and, especially, gravity effect, which is caused by insufficiently high range of real motion velocities. Exploration of possibilities of reducing the influence of these factors and, in particular, of gravity effect is one of the basic part of this study.

Large-scale deformations of a cavity under the effect of gravity in a range of insufficiently high velocities of motion can make impossible the motion of rigid hulls/bodies with small gaps between the body and water surfaces, which would otherwise provide a considerable drag reduction during their motion. Effect of free border closeness of also leads to essential reduction of cavity dimensions, including size of its maximal radius and, especially, cavity length. The fluid weightiness effect on supercavitation flows was investigated in numerous theoretical and experimental studies [1-9]. The fluid weightiness effect at insufficiently high velocities of motion leads to considerable cavity rise and deformations of its cross-sections. Thus, fluid weightiness effect forms the intensive vortical system of a cavity, the wake/tail 

Considerable Effect of Fluid Weightiness and Closeness of Free Border

of which under strong effect of fluid weightiness is ended by two hollow vortical tubes, which provide such fast and intensive gas loss, that it makes impossible formation of a sufficiently large cavity, that would be suitable for supercavitation mode application.

Application of cavitators with a nonzero angle of attack and other lift elements can considerably reduce cavity rise and deformations of cavity cross-sections with simultaneous reduction of the intensity of vortical system, which accordingly implies less intensity of gas loss/entrainment from a cavity in gas injection mode. Actually, study of this process is connected with research of interaction of the vortical systems formed due to action of elevating power and gravity field on the streamlined flow. Among the pioneer studies of this interaction one can name work [10] and a number of other studies, which at some extent are related to these processes, such as $[7,9,11$, 13].

This work is devoted to elaboration on the basis of theoretical and experimental studies of a calculation technique of optimization of processes for reducing the effect of liquid weightiness on distortion of cavity shape, in order to provide motion of bodies/hulls within a cavity in a range of considerably smaller motion velocities.

The article structure includes:

- the experimental data on motion extended cavitators at a nonzero angle of attack near water surface;

- elaboration of effective practical calculation methods for a cavity in the infinite flow and taking into account the effect of free border;

- development of methods for assessment of the effect of gravity and elevating power of cavitators with reference to optimization of processes of reducing the liquid weightiness effect on cavitation flow.

The experiments are aimed at exploration of possibilities for the optimum compensation of the effect of forces of liquid weightiness from the standpoint of possibilities of obtaining nearly axisymmetrical cavity shapes for the range of much lower motion velocities.

The aim of theoretical studies consists in working out of methods and optimization design procedures for cavitation flows taking into account their verification via the experimental data obtained.

\section{Results of Experimental Studies}

The experimental results on supercavitation flows past cavitators of typical shapes, including a cone and a cone with the blunted nasal part, near water surface at various angles of attack, velocities of motion and cavitatation numbers are presented below. The experiments are conducted using a high-velocity bench of the Institute of Hydromechanics in Kiev, Ukraine with the following cavitation channel dimensions: length-140 m, width-4 m, depth 1.8-1.1 m. The experimental studies via this high-velocity bench with detailed description of the experimental technique of studies can be found elsewhere [14-16].

The basic parameters used for representation of the experimental results are as follows: $\gamma$ is cone opening semi-angle, $\mathrm{d}$ is cavity diameter in flow separation section, $\mathrm{H}$ is depth of the center of flow separation section, $U_{\infty}$ is constant velocity of motion, and $\sigma=\left(\mathrm{P}_{\infty}-\mathrm{P}_{\mathrm{c}}\right) / \frac{\rho \mathrm{U}_{\infty}^{2}}{2}$ is cavitation number corresponding to depth $\mathrm{H}$. Here $\left(\mathrm{P}_{\infty}-\mathrm{P}_{\mathrm{c}}\right)$ is pressure difference in outer flow and in cavity, $\rho$ water mass density. Figs. 1 and 2 illustrate the shapes of cavities formed at depth $\mathrm{H}=10 \mathrm{~cm}$ behind a cone and a complex-shaped cavitators, respectively.

\section{Hydrodynamic Forces At Cavitator}

Possibilities of inducing significant lift forces at disks and cones with large opening angles are quite limited. Much more effective here is application of extended cavitators, which elevating force can be improved by small wings with mainly continuous mode 
Hydrodynamics of Supercavitating Bodies at an Angle of Attacks under Conditions of Considerable Effect of Fluid Weightiness and Closeness of Free Border
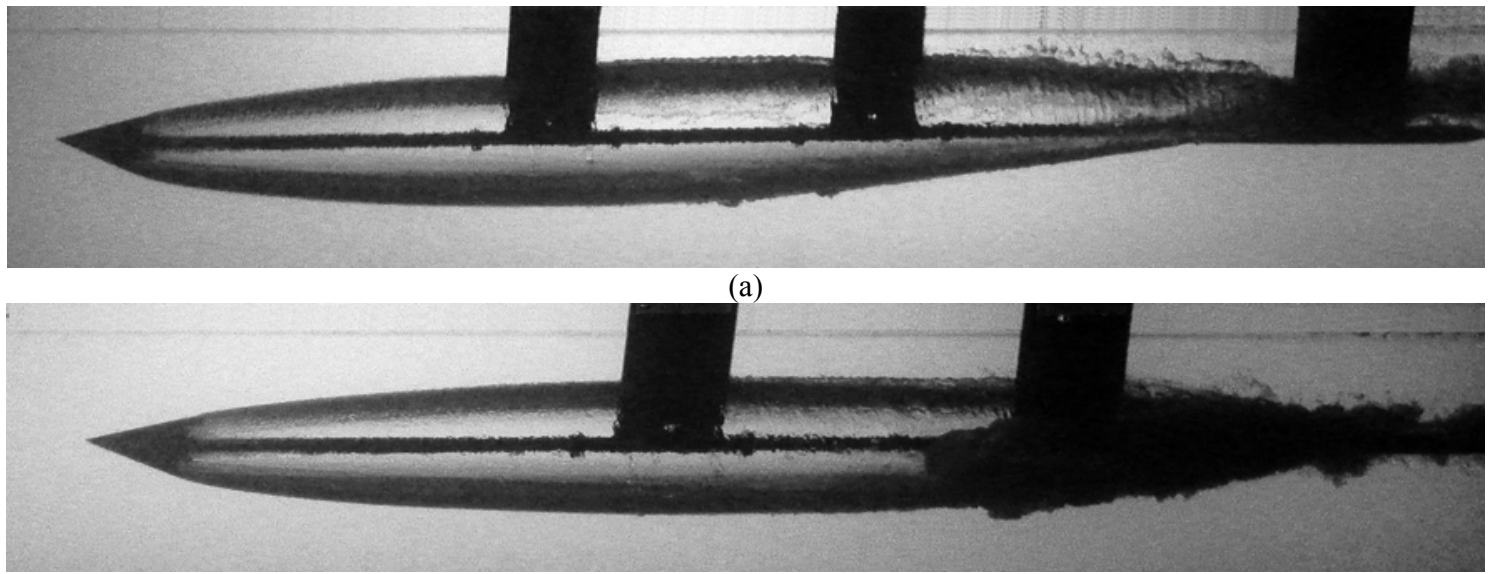

(b)

Fig. 1 A cavity behind the cone: $\gamma=20^{\circ}, d=5 \mathrm{~cm}, \alpha=5^{\circ}$, motion at depth $-H=10 \mathrm{~cm}$, a) $U_{\infty}=7.75 \mathrm{~m} / \mathrm{s}, \sigma=0.062$; b) $\mathrm{U}_{\infty}=9.75 \mathrm{~m} / \mathrm{s}, \quad \sigma=0.039$.

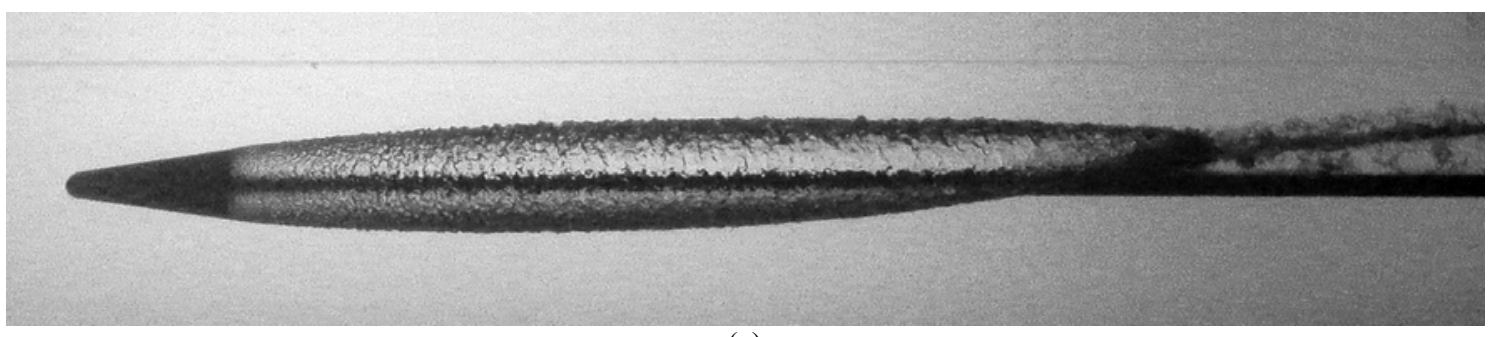

(a)

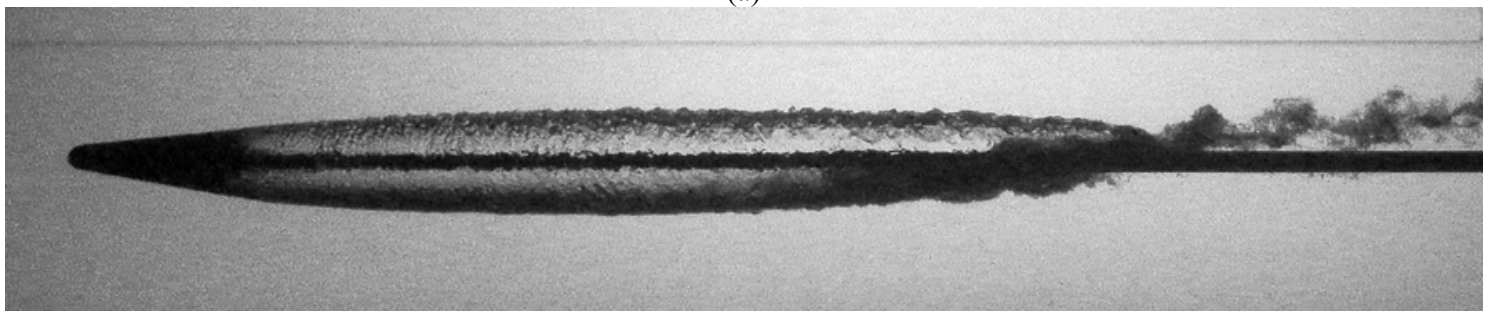

(b)

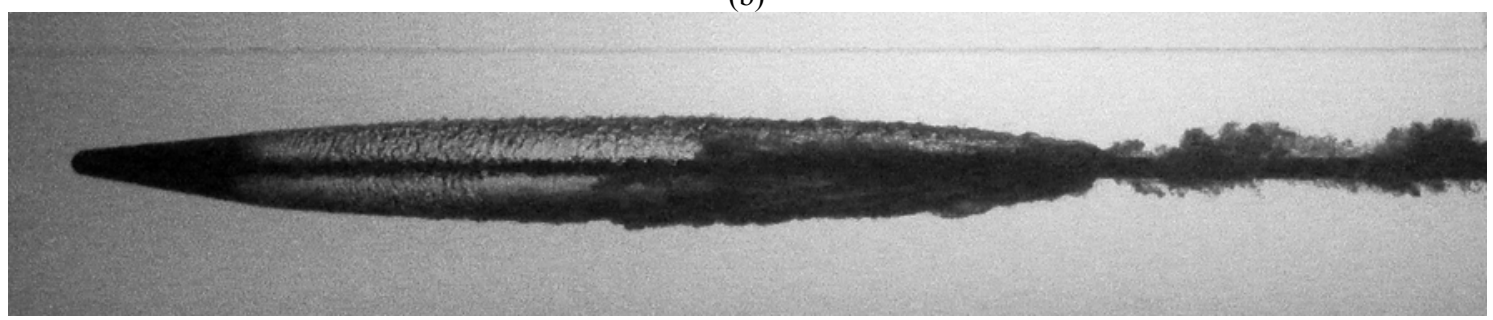

(c)

Fig. 2 A cavity behind the complex-shaped cavitator with the forward spherical front part Forward part in diameter $d_{n}=0.9 \mathrm{~cm}$ plus the conical rear part with cone opening semi-angle $-\gamma=10^{\circ}$, diameter $d=5 \mathrm{~cm}$, motion at depth $\mathrm{H}=10 \mathrm{~cm}$. a) $\left.\left.\alpha=0 \quad \mathrm{U}_{\infty}=7.75 \mathrm{~m} / \mathrm{s} \quad \sigma=0.074, \mathbf{b}\right) \alpha=2.5^{\circ} \quad \mathrm{U}_{\infty}=7.75 \mathrm{~m} / \mathrm{s} \quad \sigma=0.075, \mathbf{c}\right) \alpha=2.5^{\circ} \quad \mathrm{U}_{\infty}=9.75 \mathrm{~m} / \mathrm{s}, \quad \sigma=0.058$

of flow and other lift elements. One of the most widespread shapes of extended cavitators is a conical surface. The elongated front part of this surface for higher efficiency can be replaced by more blunt paraboloid or other shapes of a surface.

The structure of drag D includes 3 basic parts:

$$
\mathrm{D}=\mathrm{c}_{\mathrm{d}} \pi \mathrm{R}_{\mathrm{n}}^{2} \rho \mathrm{U}_{\infty}^{2} / 2, \mathrm{c}_{\mathrm{d}}=\mathrm{c}_{\mathrm{do}}+\Delta \mathrm{c}_{\mathrm{d}}+\sigma
$$

Especially in the case of slender cavitators, drag can considerably depend on cavitation number. In doing so $\Delta \mathrm{c}_{\mathrm{d}}$ accounts cavity influence on the dynamical pressure on cavitatator surface, term $\sigma$ accounts 
hydrostatic pressure action. Here: $\mathrm{R}_{\mathrm{n}}$ is radius of cavitator in flow separation section, $c_{d o}$ is drag coefficient at zero cavitation number $\sigma=0$, while term $\Delta c_{d}$ accounts for cavity effect on hydrodynamic pressure at cavitator. The results of very accurate numerical simulations of cavitation flow for the range of cavitation numbers $\gamma=15^{\circ} \div 90^{\circ}$ via the symmetric Ryabushinsky scheme of cavity closure around a cone are presented in works [17-19, 20]. The numerical data for a more specific case of a flow past cones with very small opening semi-angles $\gamma=2.5^{\circ}, 5^{\circ}, 10^{\circ}, 15^{\circ}$ for more realistic cavity closure around a disk via the Ryabushinsky scheme are given in [21]. One of the essential peculiarities of this range unlike the range $\gamma>15^{\circ}$ is much higher effect of parameter $\Delta \mathrm{c}_{\mathrm{d}}(\sigma)$ in comparison with $\mathrm{c}_{\mathrm{do}}$. The most suitable for practical use the universal approximate dependences for the cone drag coefficients $c_{d}$ on the base of these numerical simulations [17-21] and asymptotic dependence of the work [22] are:

$$
\begin{aligned}
& \mathrm{c}_{\mathrm{d}}=\mathrm{c}_{\mathrm{do}}+\kappa_{\sigma} \sigma, \quad 0<\gamma \leq 90^{\circ}: \\
& \mathrm{c}_{\mathrm{do}}=\frac{\pi^{2} \beta(\gamma)^{2}}{2} \ln \left[\frac{1.74[1-0.45 \sqrt{\beta(\gamma)}+2 \beta(\gamma)]}{\pi \beta(\gamma)}\right]- \\
& -0.87 \beta(\gamma)^{1.7}, \beta(\gamma)=\gamma / 90 \\
& \kappa_{\sigma}=\left[0.46+0.39 \beta(\gamma)+\frac{0.89 \cdot 0.017}{\beta(\gamma)^{1.36}+0.028}\right]
\end{aligned}
$$

The value of $c_{d}$ for a slender cavitators of different forward forms, but with conical back part essentially depend on their aspect ratio only. So dependencies (1) can be used for estimation of $c_{d}$ for such cavitators too especially in the case of small sizes of forward part used in the experiment Fig. 2.

Results of calculation of drag coefficients $c_{d}$ on the base of the dependence (2) as compared to date of nonlinear numerical simulations $[17,19,21]$ are illustrated by Fig. 3 .

Results of calculations on the base of dependencies (1) are confirmed also by experimental date.

Fig. 4 illustrates results of experimental determination of parameter $c_{d o}$ of cones in the range of $0<\gamma \leq 90^{\circ} \quad$ [9].

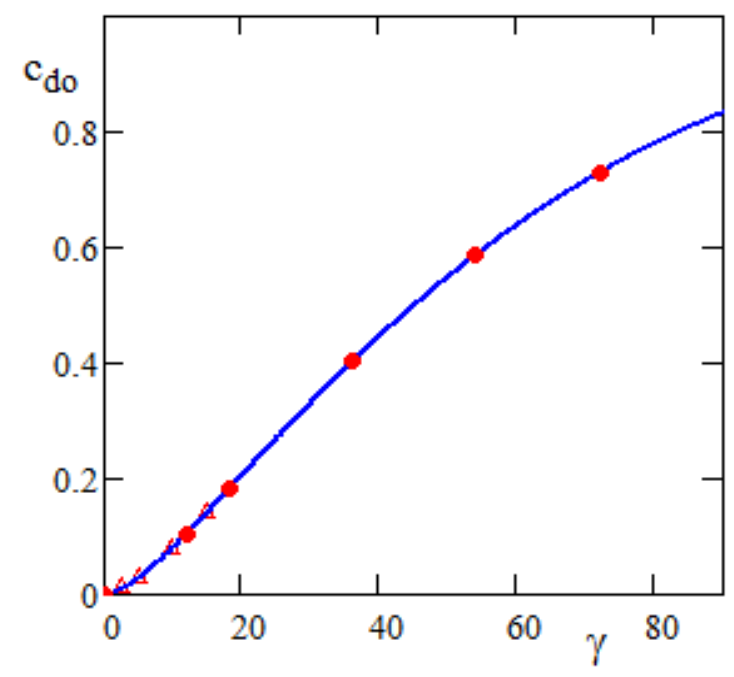

Fig. 3 Universal approximating dependence for cone $c_{d o}$. Dependence (2), $\gamma=0 \div 90^{\circ}$.

- - - nonlinear numerical simulation $[17,19]$

$\Delta \Delta \Delta \Delta$ nonlinear numerical simulation [21].

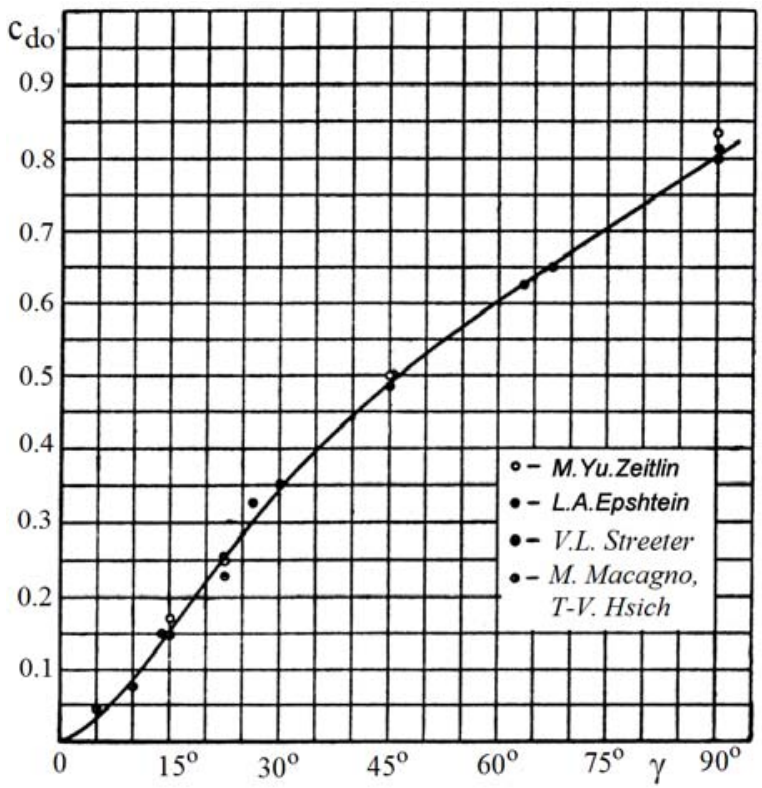

Fig. 4 Experimental data on cone $c_{d o}$ for cones semi-angle range: $0<\gamma \leq 90^{\circ}$ [2].

Lift force of an extended cavitator $\mathrm{D}_{\mathrm{y}}$, and in particular, of a cone, is derived by the well-known linear dependence:

$$
\mathrm{D}_{\mathrm{y}}=\alpha \pi \mathrm{R}_{\mathrm{n}}^{2} \rho \mathrm{U}_{\infty}^{2} / 2, \mathrm{c}_{\mathrm{dy}} \approx \alpha \div 2 \alpha
$$

Number experimental data confirm a good accuracy of dependence (3). in particular, for cone with opening semi-angle up to $\gamma \gamma \leq 20^{\circ}$. But here essential singularities are. The value $\mathrm{c}_{\mathrm{dy}} \approx 2 \alpha$ are confirmed 

Considerable Effect of Fluid Weightiness and Closeness of Free Border

by experiments in open high speed benches with moving models in particular in the work [10]. The value $\mathrm{c}_{\mathrm{dy}} \approx \alpha$ can be in some cavitational tubes [23] with low enough speed of flows.

Physically, this dependence (3) derives $D_{y}$ is defined via the attached mass in the section of flow separation on the basis of ideal model fluid. In the case of small perturbed flow and suitably slender cavitators semi-angles time of interaction of the cavitator surface with section of motionless fluid is small and it would rather the flow can be stable and similar to ideal model. In this case up and bottom part of cavitator surface are working ones and $\mathrm{c}_{\mathrm{dy}} \approx 2 \alpha$

However if we have not high enough speed and essential perturbation of moving flow for example in cavitational tube, the flow on up cavitator surface can be far from ideal model and this part surface can be fully or at least particularly not working. In this case the lift coefficient value can be $c_{d y} \sim \alpha$.

\section{Cavity Shape Prediction}

For shape of slender axisymmetric cavities calculation the system of elementary equations $(4 a-4 b)$ can be used. This system is universally applicable for

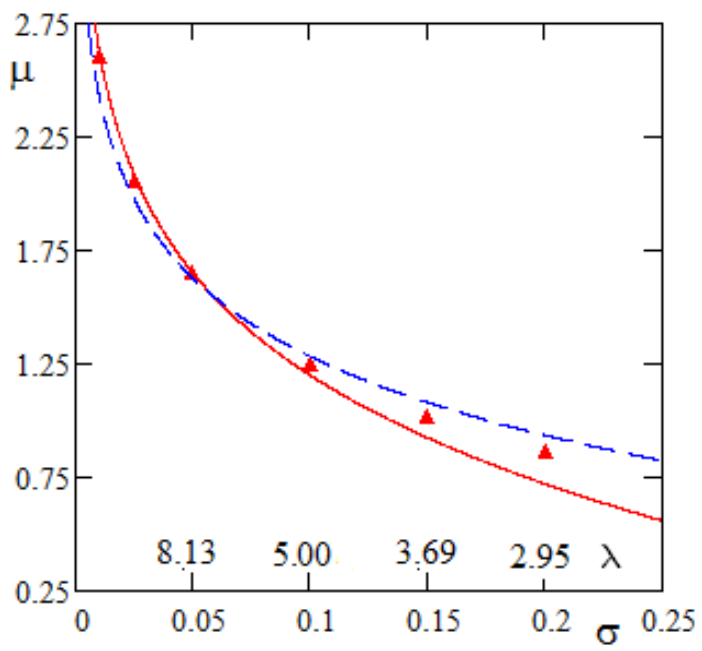

Fig. 5 The inertial factor $\mu$ controlling a typical cavity aspect ratio $\lambda$ vs cavitation number

Asymptotic approximation Eq. (5b)

- - - Asymptotic approximation Eq. (5c)

A A - value $0.5 \sigma \lambda^{2}$ which is based on nonlinear numerical simulation [18] disk-type cavitators and for slender cavitators of various shapes and, in particular, a cone with small opening semi-angles [25-27]:

(a) $\mu_{c} \frac{d^{2} R^{2}}{d x^{2}}+\sigma(x)=0$,

(b) $\left.\frac{\mathrm{dR}^{2}}{\mathrm{dx}}\right|_{\mathrm{x}=0}=\mathrm{R}_{\mathrm{n}} \sqrt{\frac{2 \mathrm{c}_{\mathrm{d}}-\mathrm{k} \sigma}{\mathrm{k} \mu_{\mathrm{c}}}},\left.\mathrm{R}^{2}\right|_{\mathrm{x}=0}=\mathrm{R}_{\mathrm{n}}^{2}$

(c) $\left.\frac{\mathrm{dR}^{2}}{\mathrm{dx}}\right|_{\mathrm{x}=0}=\mathrm{R}_{\mathrm{n}} \sqrt{\frac{2 \mathrm{c}_{\mathrm{d}}}{\mathrm{k} \mu}},\left.\mathrm{R}^{2}\right|_{\mathrm{x}=0}=0$

More simple is the system at the small cavitator for $\sigma \rightarrow 0$, which dimensions are negligible in comparison with a cavity sizes. This case is described by equation (4a) for initial conditions (4c) [24, 27]. Here values $\mu_{\mathrm{c}}$ and $\mathrm{k}$ in equations (4) are derived from the following dependences:

a) $\mu_{\mathrm{c}}=\left(\frac{\mathrm{c}_{\mathrm{d}}}{0.82-\mathrm{k} \sigma}\right) \mu$,

b) $\mu \approx \ln \frac{\lambda+0.9}{\sqrt{\mathrm{e}}}$, c) $\mu \approx \ln \sqrt{\frac{1.3}{\sigma}}$,

d) $\mathrm{k} \approx \mathrm{k}_{\mathrm{v}}\left\{1-\frac{2 \ln 2 / \sqrt{\mathrm{e}}}{\ln [(4 / \sigma)+18]}\right\}$, e) $\mathrm{k}_{\mathrm{v}} \sim 1.035$.

Parameter $\mu$-Fig. 5 is the inertial factor which is derived on the basis of solution for a cavity formed behind a small cavitator at small cavitation numbers $\sigma=$ const . Values of $\mu$ in a very wide range practically do not depend on the cavity and cavitator shape for various cases of flow but dependence on the cavity aspect ratio can be essentially considerable.

These features of parameter $\mu$ comply with the well-known principle of "independence of cavity expansion" [7], which has been confirmed by numerous experiments, as well as asymptotic and numerical solutions. Thus, asymptotic approximations (5b) which are corrected by date of numerical calculations [17-19, 21] are suitable also for a cavity both behind disk and also behind an slender cone with opening semi-angle $\sim \gamma>2^{0} \div 3^{\circ}$ in the range of cavitation numbers $\sigma \sim 0.2 \div 0.02$ and less. Dependence $5 \mathrm{a}$ includes a small correction, which account for cavitator dimensions at insufficiently small cavitation numbers. 
The factor $\mathrm{k}$ is derived by asymptotic dependence (5d) [26], which has been corrected on the basis of nonlinear numerical simulations $[19,21]$ also for a case of flow past a cone with opening semi-angle up to $\gamma>7^{\circ}$. The value of $\mathrm{k}_{\mathrm{v}}$, accounting effect of viscosity, was derived on the basis of experimental data. The factor $\mathrm{k}$ is very weakly depending value and it's usual value can be $\mathrm{k} \sim 0.96$ [7].

The problem solution (4a-c) fort $\sigma=$ const in form of an ellipsoid cavity is as follows [25, 26]:

$$
\mathrm{R}^{2}=\mathrm{R}_{\mathrm{n}}^{2}+\mathrm{R}_{\mathrm{n}} \sqrt{\frac{2\left(\mathrm{c}_{\mathrm{d}}-\mathrm{k} \sigma\right)}{\mathrm{k} \mu_{\mathrm{e}}}} \mathrm{x}-\frac{\sigma}{2 \mu_{\mathrm{e}}} \mathrm{x}^{2}
$$

This solution of Eq. (6) controls the basic dimensions of a cavity: the maximal radius $R_{k}$,

distance from flow separation section to the midsection of cavities $L_{m}$, length of the rear part of a cavity after the midsection $\mathrm{L}_{\mathrm{k}}$ and full length of a cavity $L_{c}=L_{n}+L_{k}$. The doubled elongation of the rear part of the cavity: $\lambda_{k}=L_{k} / R_{k}$ is equal to cavity elongation for a small disk-type cavitator.

A cavity main sizes are defined by dependencies:
a) $\mathrm{R}_{\mathrm{k}}=\mathrm{R}_{\mathrm{n}} \sqrt{\frac{\mathrm{c}_{\mathrm{d}}}{\mathrm{k} \sigma}}$, b) $\mathrm{L}_{\mathrm{m}}=\frac{\mathrm{R}_{\mathrm{n}}}{\sigma} \sqrt{\frac{2\left(\mathrm{c}_{\mathrm{d}}-\mathrm{k} \sigma\right) \mu_{\mathrm{c}}}{\mathrm{k}}}$,
c) $\mathrm{L}_{\mathrm{k}}=\frac{\mathrm{R}_{\mathrm{n}}}{\sigma} \sqrt{\frac{2 \mathrm{c}_{\mathrm{d}} \mu_{\mathrm{c}}}{\mathrm{k}}}$, d) $\lambda_{\mathrm{k}}^{2}=\frac{2 \mu_{\mathrm{c}}}{\sigma}$
e) $L_{c}=\frac{R_{n}}{\sigma} \sqrt{\frac{2 \mu_{c}}{k}}\left(\sqrt{c_{d}-k \sigma}+\sqrt{c_{d}}\right)$

Note also that the well-known dependence for $\mathrm{R}_{\mathrm{k}}$ has been obtained by various ways in a number of works, starting from pioneer studies of $\mathrm{H}$. Reichardt, G. Logvinovich, and L. Epshtein.

The accuracy of calculations of cavity shape based on the system (4) has been verified using multiple nonlinear simulation results and experimental data. Accuracy of calculation of the cavity shape on the basis of solution (6), in comparison with the data of numerical simulation [21], is illustrated by Fig. 6 .

\section{Effect of a Free Border}

Attempts of solving the problem of calculation of free border effect on the shape and dimensions of a cavity were undertaken in a number of works $[9,13$, 28]. However, there is a number of questions concerning the accuracy and the range of applicability of these studies. In the present work, for calculation of the effect of free border on the shape and dimensions of a cavity we use the model of mirror display of flow potential with the potential of a fictitious flow of the opposite sign. The potential of a fictitious flow, similarly to work $[13,28]$, is also approximated by a flow from a source and a drain with the maximum section area equal to the area of perturbed flow under the effect of free border with an opposite sign. However, for calculation of the shape of a cavity taking into account the effect of free border) the limiting variant of system of equations $(4 a, 4 c)$ is applied to a cavity behind a small cavitator. Value of the additional pressure (cavitation number $\Delta \sigma$ ) is derived from the following dependence:

$$
\Delta \sigma=\frac{\overline{\mathrm{R}}_{\mathrm{f}}^{2}}{2}\left\{\frac{\overline{\mathrm{x}}}{\left[\overline{\mathrm{x}}^{2}+(2 \overline{\mathrm{H}})^{2}\right]^{3 / 2}}+\frac{\left(\overline{\mathrm{L}}_{\mathrm{f}}-\overline{\mathrm{x}}\right)}{\left[\left(\overline{\mathrm{L}}_{\mathrm{f}}-\overline{\mathrm{x}}\right)^{2}+(2 \overline{\mathrm{H}})^{2}\right]^{3 / 2}}\right\}
$$

The solution is represented as the superposition the cavity shape at $\sigma=$ const and its perturbation under

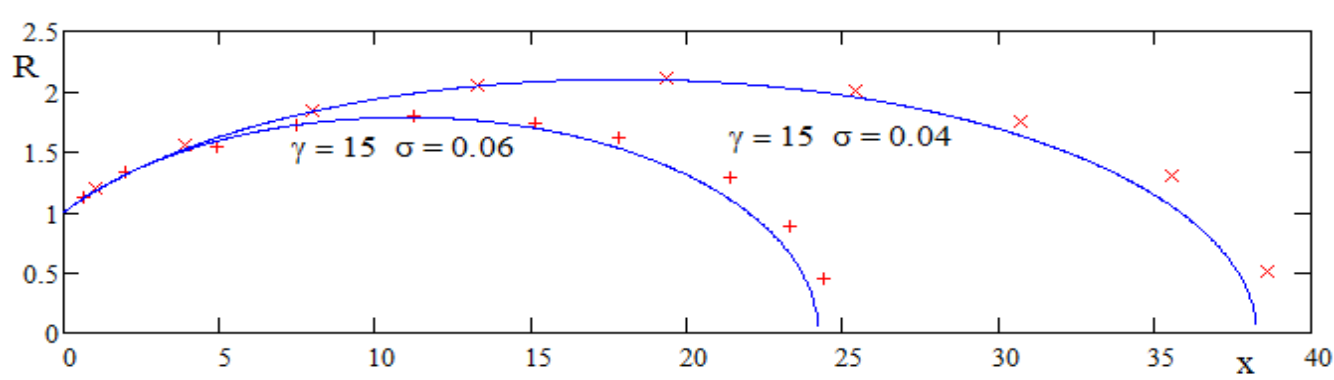

Fig. 6 Verification of accuracy of solution Eq. 6 for the shape of cavity behind a cone

Cone semi-angle - $\gamma=15, \sigma=0.04, \sigma=0.06$ :

- Solution Eq. (6);,$++++ \times \times \times \times-$ Nonlinear numerical simulation [21] 
the effect of a free border for longitudinal dimensions normalized by scale $\mathrm{L}_{\mathrm{k} \Delta}=\sqrt{\mu_{\mathrm{f}} / \mu_{\mathrm{c}}} \mathrm{L}_{\mathrm{k}}$ :

$$
\begin{gathered}
\frac{\mathrm{R}_{\mathrm{f}}^{2}}{\mathrm{R}_{\mathrm{k}}^{2}}=\overline{\mathrm{x}}(2-\overline{\mathrm{x}})- \\
-\frac{1}{2 \mu_{\mathrm{f}}} \frac{\mathrm{R}_{\mathrm{f}}^{2}}{\mathrm{R}_{\mathrm{k}}^{2}} \int_{0}^{\overline{\mathrm{x}}} \int_{0}^{\overline{\mathrm{x}}}\left(\frac{\overline{\mathrm{x}}}{\left[\overline{\mathrm{x}}^{2}+(2 \overline{\mathrm{H}})^{2}\right]^{3 / 2}}+\right. \\
\left.+\frac{\left(\overline{\mathrm{L}}_{\mathrm{f}}-\overline{\mathrm{x}}\right)}{\left[\left(\overline{\mathrm{L}}_{\mathrm{f}}-\overline{\mathrm{x}}\right)^{2}+(2 \overline{\mathrm{H}})^{2}\right]^{3 / 2}}\right) \mathrm{d} \overline{\mathrm{x}} \mathrm{x}
\end{gathered}
$$

Here $\overline{\mathrm{R}}_{\mathrm{f}}=\mathrm{R}_{\mathrm{f}} / \mathrm{L}_{\mathrm{k} \Delta}, \overline{\mathrm{L}}_{\mathrm{f}}=\mathrm{L}_{\mathrm{f}} / \mathrm{L}_{\mathrm{k} \Delta}$, whereas $\mathrm{R}_{\mathrm{f}}$ and $L_{f}$ are the maximal radius and semi-length of the perturbed cavity, respectively, $L_{k}$ is semi-length of unperturbed cavity in an infinite flow; $\mu_{\mathrm{f}}$ and $\mu_{\mathrm{c}}$ are inertial factors for perturbed and unperturbed flow, respectively. Within the application limits of dependence (9) for $\Delta \sigma$, a symmetry of the perturbed cavity takes place, whereas within framework of the problem statement, the cavitator drag is assumed to be identical to that in the unperturbed flow or that preset in the independent way. The problem for definition of values $R_{f}$ and $L_{f}$ was solved numerically on the basis of following system of equations:

a) $\left.\left\{\mathrm{R}\left[\left(\mathrm{R}_{\mathrm{f}} / \mathrm{R}_{\mathrm{k}}\right) \overline{\mathrm{L}}_{\mathrm{f}}, \overline{\mathrm{x}}\right] / \mathrm{R}_{\mathrm{k}}\right\}^{2}\right|_{\overline{\mathrm{x}}=2 \overline{\mathrm{L}}_{\mathrm{c}}}=0$,

b) $\left.\left\{\mathrm{R}\left[\left(\mathrm{R}_{\mathrm{f}} / \mathrm{R}_{\mathrm{k}}\right) \overline{\mathrm{L}}_{\mathrm{f}}, \overline{\mathrm{x}}\right] / \mathrm{R}_{\mathrm{k}}\right\}^{2}\right|_{\overline{\mathrm{x}}=\overline{\mathrm{L}}_{\mathrm{c}}}=\mathrm{R}_{\mathrm{f}} / \mathrm{R}_{\mathrm{k}}$,

c) $\overline{\mathrm{H}}=\mathrm{H} / \mathrm{L}_{\mathrm{k}} \sqrt{\mu_{\mathrm{c}} / \mu_{\mathrm{f}}}$

d) $\mu_{\mathrm{f}}=\frac{0.82}{0.82-\mathrm{k} \sigma} \ln \left[\frac{1}{\sqrt{\mathrm{e}}}\left(\frac{\overline{\mathrm{L}}_{\mathrm{f}}}{\left(\mathrm{R}_{\mathrm{f}} / \mathrm{R}_{\mathrm{k}}\right)} \frac{\mathrm{L}_{\mathrm{k}}}{\mathrm{R}_{\mathrm{k}}} \sqrt{\frac{\mu_{\mathrm{f}}}{\mu_{\mathrm{c}}}}+1.12\right)\right]$

In the process of solving for a wide range of possible initial dimensions, it was revealed that the shape of cavities under the free border effect was close to ellipsoidal. This allows one to represent the results of the solution in the form of dependence for solutions in the infinite flow with correction of $c_{d}, \sigma$, and $\mu_{\mathrm{e}}$ values by adjustment factors $\kappa_{\mathrm{cd}}, \kappa_{\sigma}$, and $\kappa_{\mu}$.

Dimensions $L_{f}$ and $R_{f}$ for a perturbed cavity are also derived on the basis of the unperturbed solution by means of similar factors $\kappa_{R}\left(R_{f}=\kappa_{R} R_{k}\right)$ and
$\kappa_{\mathrm{Lo}}\left(\mathrm{L}_{\mathrm{f}}=\kappa_{\mathrm{Lo}} \sqrt{\kappa_{\mu}} \mathrm{L}_{\mathrm{k}}\right)$. The interrelation between these values is derived from the following dependences

$$
\begin{aligned}
& \kappa_{\mathrm{cd}}=\left(\frac{\kappa_{\mathrm{R}}^{2}}{\kappa_{\mathrm{Lo}}}\right)^{2}, \kappa_{\sigma}=\frac{\kappa_{\mathrm{R}}}{\kappa_{\mathrm{Lo}}}, \\
& \mathrm{R}^{2}=\mathrm{R}_{\mathrm{n}}^{2}+\mathrm{R}_{\mathrm{n}} \sqrt{\frac{2\left(\kappa_{\mathrm{cd}} \mathrm{c}_{\mathrm{d}}-\mathrm{k} \kappa_{\sigma} \sigma\right)}{\mathrm{k} \kappa_{\mu} \mu_{\mathrm{c}}}} \mathrm{x}-\frac{\kappa_{\sigma} \sigma}{2 \kappa_{\mu} \mu_{\mathrm{c}}} \mathrm{x}^{2}
\end{aligned}
$$

The initial data for calculation are given in Table 1, and Table 2. The respective results are depicted in particular in Fig. 7, whereas the basic dimensions of cavities without fluid weightiness effect are given in comparison with their shapes calculated with the account of free border effect with reference to the data of experiment illustrated by Fig. 1b.

\section{Technique for Compensation of Gravity Effect on a Cavity Shape}

As the initial dependences, the well-known equations [7] are applied to derive the cavity axis deflection by the liquid weightiness effect, $h_{g}(x)$, and that induced by the angle of attack of cavitator, $\mathrm{h}_{\alpha}$, as follows:
a) $h_{g}(x)=\frac{g}{\pi U_{\infty}^{2}} \int_{0}^{x} \frac{V_{x}}{R^{2}(x)} d x$,
b) $\mathrm{h}_{\alpha}=-\frac{\mathrm{D}_{\mathrm{y}}}{\pi \rho \mathrm{U}_{\infty}^{2}} \int_{0}^{\mathrm{x}} \frac{\mathrm{dx}}{\mathrm{R}^{2}(\mathrm{x})}$

Here $g$ s gravity acceleration, $V_{x}$ is volume of a cavity part up to section $\mathrm{x}, \mathrm{D}_{\mathrm{y}}$ is lift force of cavitator inclined at the angle of attack $\alpha$. These dependences can be refined with reference to cavities formed behind slender cavitators on the basis of solution (6) and dependences for cavitator's lift force (3) normalized by $R_{n}=1$, as follows:
a) $h_{g}(x)=\frac{g_{n}}{U_{\infty}^{2}} \int_{0}^{x} \frac{x\left(1+\frac{b}{2} x-\frac{c}{3} x^{2}\right)}{1+b x-c x^{2}} d x$,
b) $\mathrm{h}_{\alpha}=-\frac{\tan \alpha}{2} \int_{0}^{\mathrm{x}} \frac{\mathrm{dx}}{1+\mathrm{bx}-\mathrm{cx}^{2}}$
c) $\left.b=\sqrt{\frac{2\left(c_{d}-k \sigma\right)}{k \mu_{c}}}, d\right) c=\frac{\sigma}{2 \mu_{c}}$, 


\begin{tabular}{|c|c|}
\hline Table 1 Ex & ble 2 Expe \\
\hline $\begin{array}{l}\text { Initial data - a conic cavitator: } \\
\text { Cone radius in flow separation section: } \mathrm{R}_{\mathrm{n}}=2.5 \mathrm{~cm} \\
\text { Cone opening semi-angle: } \gamma=20^{\circ} \\
\text { Depth of the cavity axis: } \mathrm{H}=10 \mathrm{~cm} \\
\text { Velocity of motion: } \mathrm{U}_{\infty}=9.75 \mathrm{~m} / \mathrm{s} \\
\text { Cavitation number: } \sigma=0.039 \\
\text { Angle of attack of cavitator: } \quad \alpha=5^{\circ}\end{array}$ & $\begin{array}{l}\text { Initial data - a composite-shaped cavitator } \\
\text { Cavitator radius in flow separation section }: \mathrm{R}_{\mathrm{n}}=2.5 \mathrm{~cm} \text {, Radius } \\
\text { of the spherical surface inscribed into the conic front } \\
\text { part- } 0.45 \mathrm{~cm} \\
\text { Opening semi-angle of cavitator's back conic part: } \gamma=20^{\circ} \\
\text { Depth of the cavity axis: } \mathrm{H}=10 \mathrm{~cm} \\
\text { Velocity of motion: } \mathrm{U}_{\infty}=9.75 \mathrm{~m} / \mathrm{s} \\
\text { Cavitation number: } \sigma=0.058 \div 0.059 \\
\text { Angle of attack of cavitator: } \quad \alpha=2.5^{\circ}\end{array}$ \\
\hline $\begin{array}{l}\text { Calculation results without weightiness and free bord } \\
\text { effects }\end{array}$ & $\begin{array}{l}\text { Calculation results without weightiness and free border } \\
\text { effects }\end{array}$ \\
\hline $\begin{array}{l}\mathrm{c}_{\mathrm{d}}=0.231, \quad \mu_{\mathrm{c}}=1.91, \quad \mathrm{k}=0.956 \\
\mathrm{R}_{\mathrm{k}}=0.062 \mathrm{~m}, \quad \mathrm{~L}_{\mathrm{c}}=1.18 \mathrm{~m}, \quad \mathrm{~L}_{\mathrm{k}}=0.616, \quad \lambda_{\mathrm{k}}=9.9\end{array}$ & $\begin{array}{l}\mathrm{c}_{\mathrm{d}}=0.126, \quad \mu_{\mathrm{c}}=1.74, \mathrm{k}=0.95 \\
\mathrm{R}_{\mathrm{k}}=0.048 \mathrm{~m}, \quad \mathrm{~L}_{\mathrm{c}}=0.678 \mathrm{~m}, \quad \mathrm{~L}_{\mathrm{k}}=0.367, \quad \lambda_{\mathrm{k}}=7.71\end{array}$ \\
\hline
\end{tabular}

\begin{tabular}{|c|c|}
\hline $\begin{array}{l}\text { Adjustment factors for cavity shape and dimensions under } \\
\text { free border effect }\end{array}$ & $\begin{array}{l}\text { Adjustment factors for calculation of cavity shape and } \\
\text { dimensions under free border effect }\end{array}$ \\
\hline$\kappa_{\mathrm{R}}=0.869, \quad \kappa_{\mathrm{Lo}}=0.755, \quad \kappa_{\mu}=0.965$ & $\kappa_{\mathrm{R}}=0.926, \quad \kappa_{\mathrm{Lo}}=0.843, \quad \kappa_{\mu}=0.979$ \\
\hline$\kappa_{\mathrm{cd}}=1.00 \quad \kappa_{\sigma}=1.325$ & $\kappa_{\mathrm{cd}}=1.035 \quad \kappa_{\sigma}=1.207$ \\
\hline Correction of values $c_{\mathrm{d} \kappa}, \sigma \kappa$ with account of free border effect & Correction of values $c_{d \kappa}, \sigma \kappa$ with account of free border effect \\
\hline $\mathrm{c}_{\mathrm{d \kappa}}=\mathrm{c}_{\mathrm{d}}=0.231, \quad \sigma \kappa=0.052$ & $\mathrm{c}_{\mathrm{d \kappa}}=0.136, \quad \sigma \kappa=0.071$ \\
\hline $\begin{array}{l}\text { Calculated results with account of free border effect, in } \\
\text { comparison with experiment }\end{array}$ & $\begin{array}{l}\text { Calculated results with account of free border effect, in } \\
\text { comparison with experiment }\end{array}$ \\
\hline $\mathrm{R}_{\mathrm{kf}}=0.054 \mathrm{~m},($ Exp.: $0.056 \mathrm{~m})$ & $\mathrm{R}_{\mathrm{kf}}=0.044 \mathrm{~m},($ Exp.: $\mathbf{0 . 0 4 4} \mathbf{~ m})$ \\
\hline $\mathrm{L}_{\mathrm{cf}}=0.862 \mathrm{~m},($ Exp.: $\mathbf{0 . 8 7 5} \mathbf{~ m})$ & $\mathrm{L}_{\mathrm{cf}}=0.557 \mathrm{~m},($ Exp.: $\mathbf{0 . 6 1 2} \mathbf{~ m})$ \\
\hline $\mathrm{L}_{\mathrm{kf}}=\kappa_{\mathrm{L}} \mathrm{L}_{\mathrm{k}}=0.454 \mathrm{~m}$ & $\mathrm{~L}_{\mathrm{kf}}=\kappa_{\mathrm{L}} \mathrm{L}_{\mathrm{k}}=0.306 \mathrm{~m}$ \\
\hline$\lambda_{\mathrm{k}}=8.45$ (Exp.: 8.2) & $\lambda_{\mathrm{kf}}=6.95 \quad$ (Exp.: 7.2$)$ \\
\hline$\mu_{\mathrm{f}}=\kappa_{\mu} \mu_{\mathrm{c}}=1.845$ & $\mu_{\mathrm{f}}=\kappa_{\mu} \mu_{\mathrm{c}}=1.703$ \\
\hline
\end{tabular}

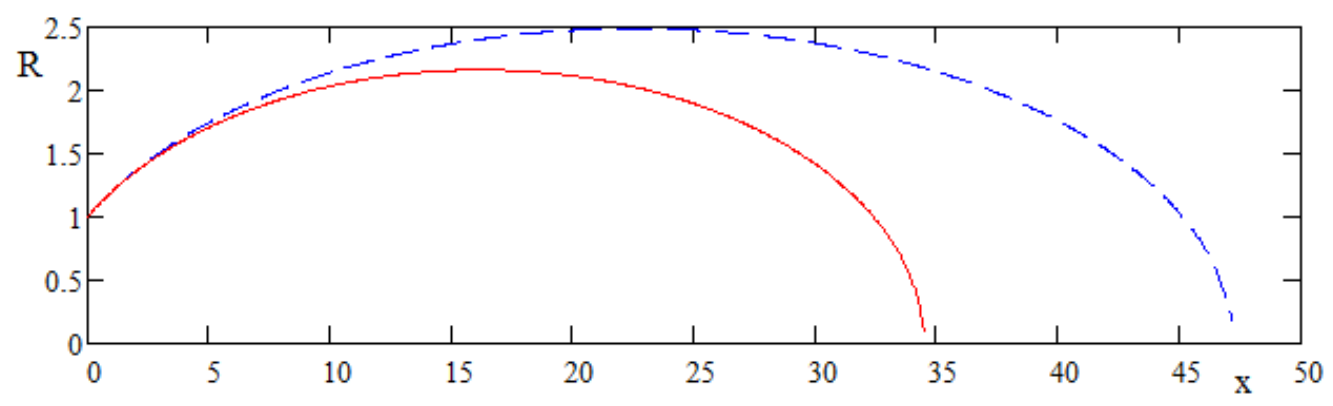

Fig. 7 Calculation results for cavity behind a cone for motion below water free border and in an infinite flow $\gamma=20^{\circ}, \mathrm{R}_{\mathrm{n}}=0.025 \mathrm{~m}, \sigma=0.039$

motion of cone at depth $\mathrm{H}=0.1 \mathrm{~m}$ below water free border; - - - motion of cone in an infinite flow.

$$
\mathrm{h}_{\mathrm{g} \alpha}=\mathrm{h}_{\mathrm{g}}+\mathrm{h}_{\alpha}
$$

As applied to a cavity below water free border, values $\mathrm{b}, \mathrm{c}$, and $\mu_{\mathrm{c}}$ in dependences (13a, 13b) should be adjusted by means of adjustment factors $\kappa_{\mathrm{cd}}, \kappa_{\sigma}$, and $\kappa_{\mu}$. The total value of deformation (axis deflection) is derived via dependence (14).

The calculated results on the joint effect of gravity and angle of attack of a cavitator with reference to the data of experiments No. 1 and No. 2 which described in Table 1 and Table 2 are illustrated by Fig. 8 and Fig. 9 , respectively.

Versus motion velocity and cavitation number via (15b)

The calculated results with reference to experiment No.1 at $\alpha=5^{\circ}$ and No.2 at $\alpha=2.5^{\circ}$ are confirmed by the data of these experiments and imply the possibility 

Considerable Effect of Fluid Weightiness and Closeness of Free Border

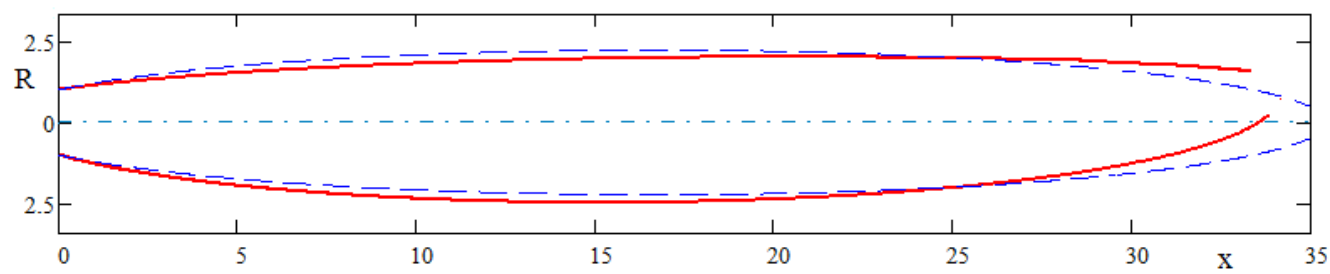

Fig. 8 Calculated results versus data of experiment No. 1 (Table 1):

A cone: $d=0.025 \mathrm{~m}, \gamma=20^{\circ}$, depth $\mathrm{H}=0.1 \mathrm{~m}, \mathrm{U}_{\infty}=9.75 \mathrm{~m} / \mathrm{s}, \sigma=0.039$, cavitator at the angle of attack at $\alpha=5^{\circ}$.

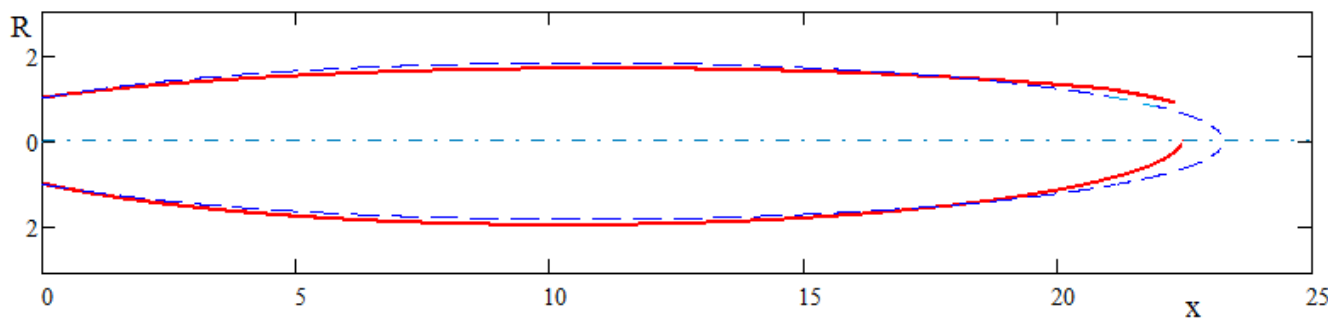

Fig. 9 Calculated results versus data of experiment No. 2 (Table 2):

A composite-shaped cavitator: a paraboloid-a cone, back conical part: $\mathrm{d}=0.025 \mathrm{~m}, \gamma=10^{\circ}$, depth $\mathrm{H}=0.1 \mathrm{~m}, \mathrm{U}_{\infty}=9.75 \mathrm{~m} / \mathrm{s}$, $\sigma=0.0585$, cavitator at the angle of attack $\alpha=3^{\circ}$.

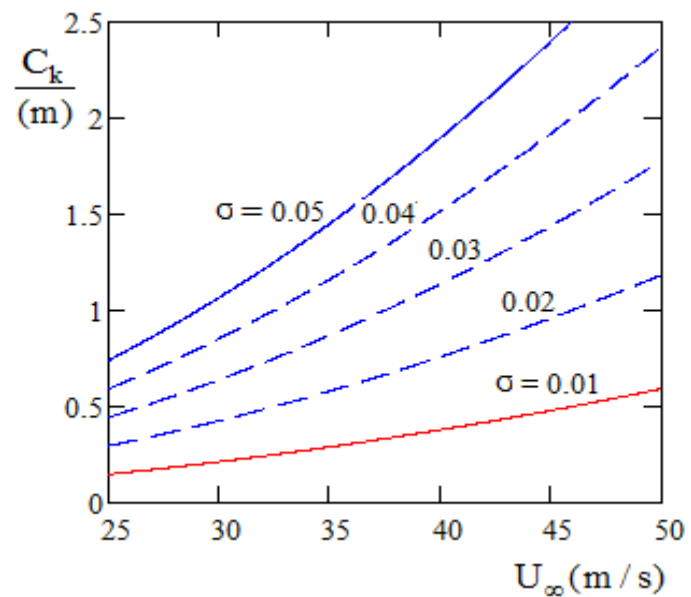

Fig. 15 Limiting diameters of a cavity, providing small deformations of cavity cross-sections.

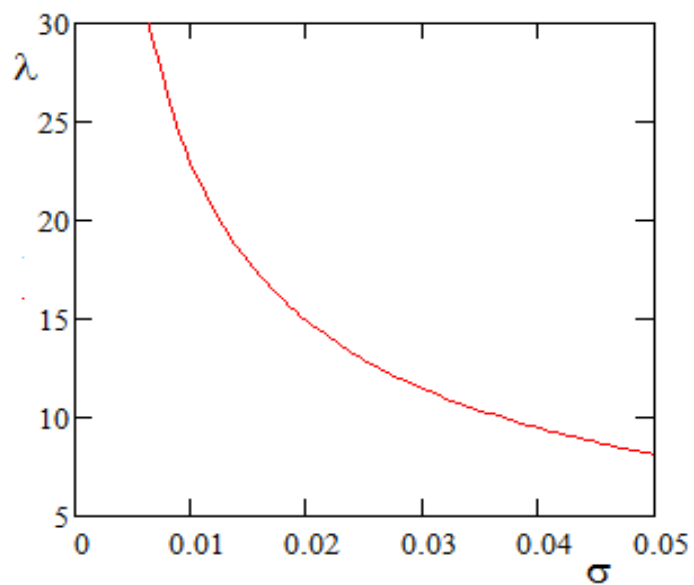

Fig. 16 Cavity aspect ratio depend on cavitation number. of successful compensation of liquid weightiness at the experimental angles of attack of a cavitator.

The problem of gravity effect compensation is related not only to suppression of cavitation deflection of cavity axis, but also to deformation of cavity cross-sections. At small level of deformations their superposition is possible with assumed independence of the effects of gravity and angle of attack on these values. Usage of the data on regular calculations [4] for deformations of a cavity behind a disk under gravity effect made it possible to identify the limit of insignificance of these deformations in the form of the modified condition (15a)

$$
\text { a) } \zeta=\operatorname{Fr}_{\mathrm{d}}^{2} \sigma \sqrt{\sigma}>4, \text { b) } \mathrm{C}_{\mathrm{k}}<\zeta_{\mathrm{s}}=\frac{\sigma \mathrm{U}_{\infty}^{2}}{4.3 \mathrm{~g}}
$$

Based on this data, the refined condition (15b) can be derived, which is also suitable for extended cavitators. In this condition, $C_{k}=2 R_{k}$, where $R_{k}$ is the maximal radius of a cavity, which is not perturbed under the effect of gravity.

The calculated results on the range of acceptable small deformations of cavity cross-sections under the effect of gravity on the basis of condition (15b) are illustrated by Fig. 15. 

Considerable Effect of Fluid Weightiness and Closeness of Free Border

Fig. 16 depicts the dependence of cavity aspect ratio (8d) behind a cavitator of a small size, in comparison with the cavity length, which allows one to estimate the possibilities for various-size bodies being inscribed into the cavity. Estimations on the basis of dependence (15b), with reference to the data of experiments Nos. 1 and 2, described in Table 1 and Table 2, using the adjusted cavitation numbers $\sigma_{\mathrm{K}}=0.052$ and $\sigma_{\mathrm{K}}=0.071$, in order to take into account the free border effect, have yielded the following inequalities: $\quad C_{k}=0.117>0.11$ and $\mathrm{C}_{\mathrm{k}}=0.16>0.09$. This means that conditions of experiment No. 1 are close to the beginning of the range of essential deformations of cavity cross-section sections, while conditions of experiment No. 2 correspond to more small deformations.

\section{Conclusions}

A possibility of essential compensation of the liquid weightiness effect, which gives rise to cavity surface deformation, by application of slender cavitators with a nonzero angle of attack is theoretically substantiated and experimentally confirmed. The calculation technique for optimizing this process is developed. The results obtained provide insight into the possibilities of this process which may be very critical from the practical application standpoint for more effective way of gravity effect compensation. This allows a considerable reduction of ranges of possible motion velocities of bodies/hulls near free water surface, that are suitable for drag reduction on the basis of application of supercaviation flow modes.

\section{Acknowledgements}

The authors express their special thanks to employees of the Office Naval Research Global in UK, which provided financing of the initial stage of studies in this area and made possible further development of these studies illustrated by the results of this publication.

\section{References}

[1] Epshtein, L. A. 1973. "Characteristics of Ventilated Cavities and Some Scale Effects." Proc. IUTAM Intern. Symp: "Unsteady Flows of Water with High Velocities." Leningrad: 173-85.

[2] Epshtein, L. A. 1975. "Developed Cavitation Flows.” In: book Pearsall I.S. Cavitation. Moscow: Mir: 73-93.

[3] Bolotin, A. F., and Dianov, D. I. 1975. "Experimental Research of Artificial Cavities behind a Disk at Various Angles of Horizontal Slope of Inflow." Experimental Hydromechanics of Vessels. No 226. Leningrad: Sudostroyenie: 53-70.

[4] Buyvol, V. N. 1975. "On the Basic Characteristic of Action of Weightiness on Slender Spatial Cavities." J. Hydromechanics (32): 54-7.

[5] Kinzel, M. P., Lindau, J. W., and Paterson, E. G., et al. 2006. "The Effects of a Free-Surface on Computed Turbulent, Super and Partitially Cavitating Flows." Proc. Sixth Intern. Symp. on Cavitation: CAV2006, the Netherlands.

[6] Knapp, R. T., Daili, J. W., and Hammit, F. G. 1970. Cavitation. New York: Mc Graw Hill.

[7] Logvinovich, G. V. 1969 Hydrodynamics of Flows with Free Boundaries. Kiev: Naukova Dumka.

[8] Terentiev, A., Kirschner, I., and Uhlman, J. 2011. The Hydrodynamics of Cavitating Flows. USA: Backbone Publishing.

[9] Zhuravlyov, Yu. F. 1973. "Methods of the Perturbation Theory for Spatial Jet Flows.” J. Proc. TsAGI (1532): 23.

[10] Kapankin, Y. N., and Gusev, A. V. 1984. "Experimental Research of Reciprocal Effect Gravity and Cavitator Lift on Nature of Flow at the Back Part of Cavity and Gas Loss from It." J. Proc.TsAGI. (2244): 19-28.

[11] Arndt, E. A. 2002. "Cavitation in Vortical Flows." $J$. Annu. Rev., Fluid Mech. (34): 143-75.

[12] Dzielski, J., Sammut, P., and Datla, R. 2012. "Planing-Hull Forces and Moments on a Cylindrical Body in a Cavity." Proc. of Eighth International Symposium on cavitation: CAV2012, Singapore.

[13] Egorov, I. T., Sadovnikov, Yu. N., Isaev, I. K., Basin, M. A. 1971. Artificial Cavitation. Leningrad: Sudostroyenie.

[14] Babenko, V., Shkwar, E., and Moroz, V. 2003. "Combined Method of Body Stabilisation in Shear Flow." Proc. 5th Int. Symp. on Cavitation: CAV2003, Osaka, Japan.

[15] Babenko, V. V., Korobov, V. I., Moroz, V. V., and Shkvar E. A. 2000. "Experimental Investigation of a Combined Method of Drag Reduction." Proc Int. Conf. on Ship and Shipping Research, NAV-2000, Venice.

[16] Kochin, V., and Moroz, V. 2009. "Automated Data Acquisition and Processing System for a High-Speed 

Considerable Effect of Fluid Weightiness and Closeness of Free Border

Towing Tank." J. Modern Technologies of Automation (3): $15-24$.

[17] Guzevsky, L. G., and Zavarzin, D. S. 2000. "Conformity between Flat and Axisymmetric Cavitaion Flows." J. Reports of the Siberian Branch of Academy of Sciences of the Higher School (1):10-7.

[18] Guzevsky, L. G. 1979. Numerical Analysis of Cavitation Flows. Novosibirsk: Preprint of Thermal Physics Institute, No. 40-79.

[19] Guzevsky, L. G. 1983. "Approximated Dependence for Axisymmetric Cavities behind Cones." Novosibirsk: Hydrodynamic Flows And Wave Processes: 82-91.

[20] Subhankulov, G. I., and Khomyakov, A. N. 1990. "Application of the Method of Boundary Elements to Calculation of Axisymmetrical Cavities." Cheboksary: Proc. of Conference High Speed Hydrodynamics: HSH-1990:124-32.

[21] Krasnov, V. K., and Kuznetsov, Yu. V. 1989. "Application of the Boundary Integrated Equation Method for Calculation of Axisymmetrical and Flat Flows in a Pipe." Cheboksary: Actual Problems of Hydrodynamics: 71-5.

[22] Taits, O. G. 1985. “Axisymmetric Cavities.” J. Bionics (19): 73-80.
[23] Kiceniuk, T. 1954. "An Experimental Study of the Hydrodynamic Forces Acting on a Family of Cavity-Producing Conical Bodies of Revolution Inclined to the Flow." Report No E-12.17. Hydrodynamics laboratory California Institute of Technology.

[24] Logvinovich, G. V., and Serebryakov, V. V. 1975. "On Methods of Shape Calculation of Axisymmetric Cavities." J. Hydromechanics (32): 47-54.

[25] Serebryakov, V. V. 2009. "Physical-Mathematical Bases of the Principle of Independence of Cavity Expansion." Proc. of Int. Symp on Cavitation: CAV2009, Ann Arbor, Michigan, USA.

[26] Serebryakov, V. V. "The Models of the Supercavitation Prediction for High Speed Motion in Water." 2002. Proc. of Int. Conference High Speed Hydrodynamic: HSH2002, Cheboksary: 71-92.

[27] Serebryakov, V. V. 1976. "On One Variant of the Equations of the Principle of Independence of Cavity Expansion." J Hydromechanics (34): 45-8.

[28] Epshtein, L. A., and Lapin, V. M. 1980. “Approximated Calculation of Flow Border Effect on Cavity Length for a Plane Problem and Behind an Axisymmetric Body." J. Proc. TsAGI, (2060): Some Studies on Hydrodynamics: 3-24. 